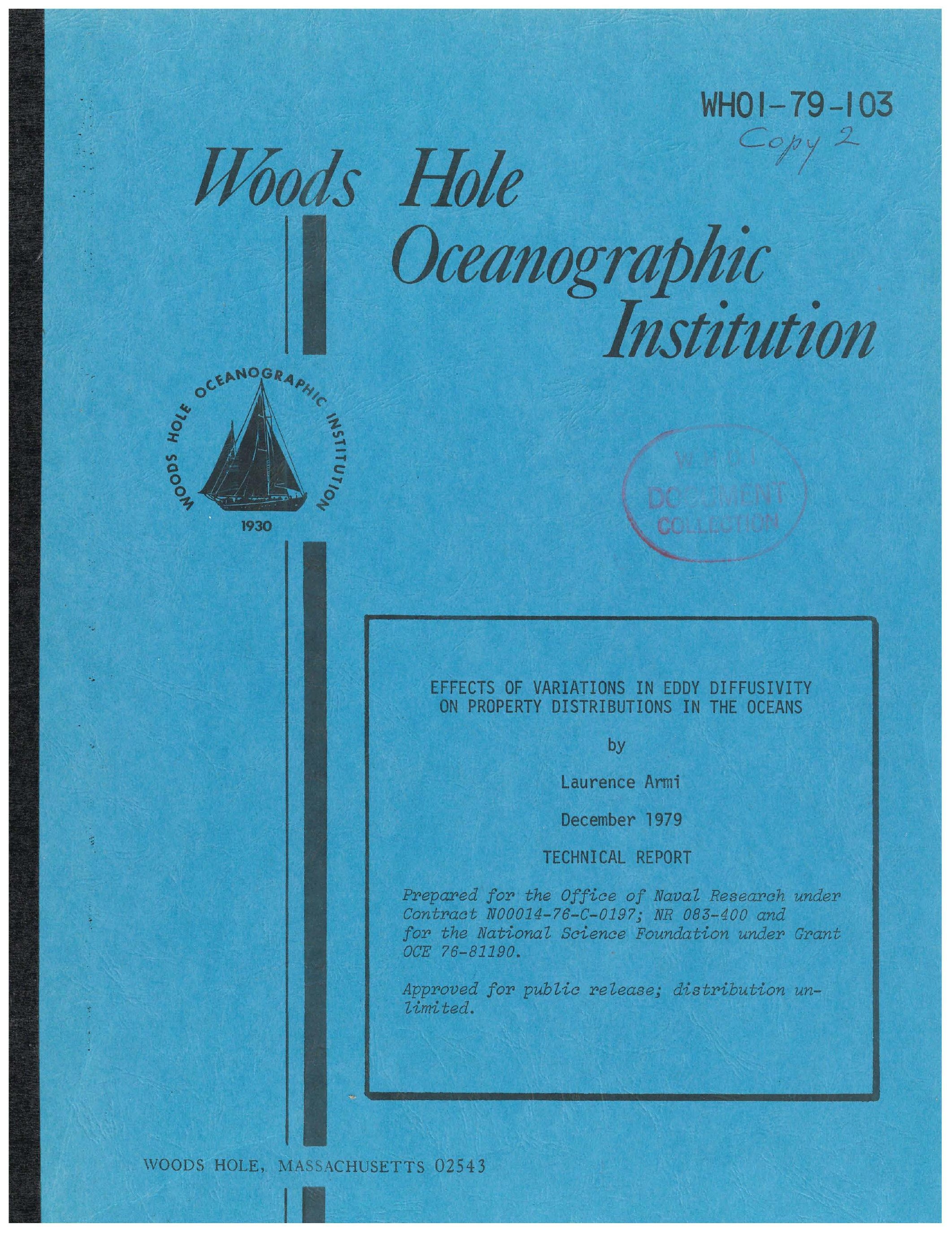


WHOI $-79-103$

\section{EFFECTS OF VARIATIONS IN EDDY DIFFUSIVITY ON PROPERTY DISTRIBUTIONS IN THE OCEANS}

by

Laurence Armi

WOODS HOLE OCEANOGRAPHIC INSTITUTION Woods Hole, Massachusetts 02543

December 1979

TECHNICAL REPORT

Prepared for the Office of Naval Research under Contract N00014-76-C-0197; NR 083-400 and for the National Science Foundation under Grant OCE 76-81190.

Reproduction in whole or in part is permitted for any purpose of the United States Government. In citing this report in a bibliography, the reference given should be to "Journal of Marine Research, Volume 37, 3, 1979, pp. 515-529".

Approved for public release; distribution untimited.

Approved for Distribution: Valentine Worthington, Chairman Department of Physical Oceanography 


\title{
Effects of variations in eddy diffusivity on property distributions in the oceans ${ }^{1}$
}

\author{
by Laurence Armi ${ }^{2}$
}

\begin{abstract}
The hypothesis that variations in eddy diffusivity may be responsible for some of the observed distributions of oceanic scalars is explored. A gradient in eddy diffusivity affects property distributions much as would an additional velocity field from regions of high to low eddy diffusivity. In support of such an interpretation, the cross-isopycnal distribution of density is compared with an eddy diffusivity prescribed by the combination of boundary mixing and isopycnal exchange. Since the surface area available for boundary mixing varies with depth, similar variations are reflected in property distributions. For isopycnal distributions, an eddy diffusivity field inferred from the eddy potential energy field description of Dantzler (1977) is compared with the salinity distribution from the Mediterranean Outflow.
\end{abstract}

\section{Introduction}

Even though many property distributions in the ocean can be interpreted as advective-diffusive attributes, either along or across isopycnal surfaces, these distributions may instead arise from a variable eddy diffusivity field. A spatially variable eddy diffusivity alone will affect property distributions much as would the combination of advection and diffusion with a constant eddy diffusivity. Expansion of the one-dimensional steady advective-diffusive equation illustrates this:

$$
\left(u-\frac{d k}{d x}\right) \frac{d c}{d x}-k \frac{d^{2} c}{d x^{2}}=0
$$

Locally, the addition of a gradient in the eddy diffusivity, $-\frac{d k}{d x}$, acts much like the advective velocity, $u$, on the distribution of a conservative property, $c$. The purpose here is to begin to explore the effects of variable eddy diffusivities on crossisopycnal and isopycnal property distributions.

The motivation for using a variable eddy diffusivity to parameterize cross-isopycnal mixing comes from experimental evidence for the importance of boundary mixing in the deep ocean. It was inferred in Armi $(1978,1979)$ that stratified fluid is

1. Woods Hole Oceanographic Institution Contribution No. 4209.

2. Woods Hole Oceanographic Institution, Woods Hole, Massachusetts, 02543, U.S.A. 
advected toward seamounts and topography from the basin interior by mesoscale eddies or the mean circulation; mixed layers are formed by boundary mixing at the topography; these boundary mixed layers separate from the topography, either because the scale of the topography is short and the flow includes separation zones or because the mesoscale flows driving the boundary mixing have finite horizontal length scales. The combined effect of these processes when repeated over and over again at various topographic sites may be parametrically disguised as a vertical eddy diffusivity in one dimensional models. The distribution of topography, i.e. surface area available for boundary mixing, is a function of depth. The apparent eddy diffusivity, due to the combination of boundary mixing and isopycnal exchange, will therefore have depth dependence which is reflected in property distributions.

The motivation for using a variable isopycnal eddy diffusivity, to parameterize horizontal mixing along isopycnals and account for the resultant isopycnal property distributions, comes from observational evidence of the variability of the oceanic eddy field. The hypothesis made here is that descriptions of the eddy energy field are qualitatively similar to the eddy diffusivity field, although the eddy energy descriptions also contain nondiffusive fluctuations such as Rossby waves. Qualitative similarities can be seen in the maps of isopycnal property distributions and eddy field maps; these will be interpreted in terms of variable eddy diffusivities.

Although aspects of both vertical and isopycnal property distributions may be interpreted as due to variable diffusivity fields, such an interpretation will be correct only in regions where the gradient of the eddy diffusivity is at least of the same order as mean advection (refer to Eqn. 1). The hypothesis here is that this may be true in some parts of the ocean whereas it is clearly not true in others, e.g. western boundary currents. One problem is that it is observationally difficult in the absence of velocity field information to distinguish effects due to advection from those due to a variable diffusion (Eqn. 1).

\section{Cross-isopycnal property distributions}

For the deep ocean, observational evidence suggests a vertical mixing-advection model in which actual cross-isopycnal mixing takes place at basin boundaries and topographic features. This boundary mixing model will provide a crude prescription for the variation with depth, or more correctly isopycnal level, of an isopycnally averaged vertical eddy diffusivity.

In concept, the boundary mixing model is reminiscent of arguments made by Iselin (1939), Montgomery (1938), Parr (1936, 1938) and Rossby (1936) on the importance of the role of lateral turbulence and isentropic mixing for waters of the thermocline; the horizontal variability of water characteristics in surface mixed layers being carried along isopycnals to form the observed thermocline. The arguments put forth here and in Armi $(1978,1979)$ are that the vertical stratification found in the deep ocean is induced by boundary layer processes, in much the same 


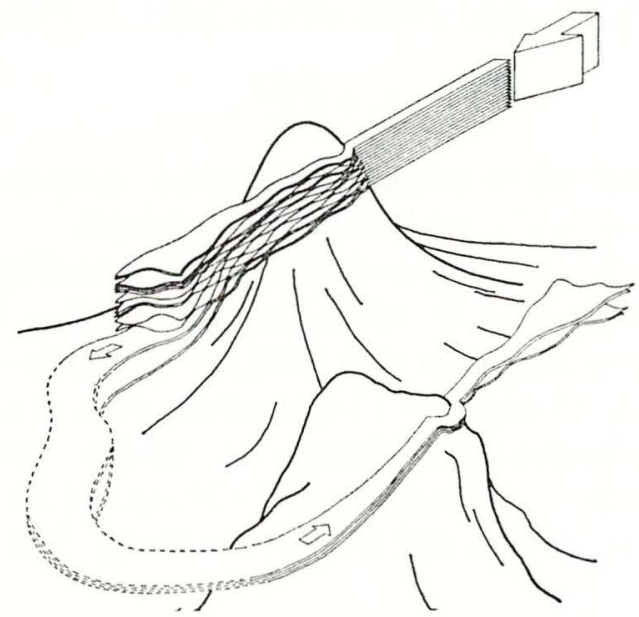

Figure 1. Sketch of boundary mixing of continuous stratification into layers and transport of mixed layers into interior. Repetition over and over again is illustrated here with dashed lines.

way that spin-up is ultimately related to Ekman layers or heat-up to side wall thermal layers (Veronis, 1967).

In cartoon form the model is illustrated in Figure 1. Stratified fluid of the deep ocean is carried past a seamount at a low bulk Froude number, $F_{s}=U / N h_{s}$, based on the velocity of the flow, $U$, the characteristic Väisälä frequency of the fluid, $N$, and height of the seamount, $h_{s}$. For such low Froude number flows, the fluid is constrained by the stratification to go round the seamount; there is insufficient kinetic energy in the approach flow to move the fluid over the seamount; with a twodimensional seamount, blocking would occur. On the seamount itself, turbulent mixed layers form by complicated processes not yet fully understood. These layers are constrained by the stable stratification such that the potential energy change associated with mixing the stratification into layers of height, $h$, is at most of the same order as the kinetic energy in the approach flow. Armi and Millard (1976) found the Froude numbers of these layers, $F_{l}=U / N h$, to be $0(2)$ or larger in the presence of topography. Similar laboratory studies of strongly stratified flow past three-dimensional obstacles have recently been reported by Brighton (1978) and Hunt et al. (1978).

This process of the stratified fluid of the deep ocean being mixed into layers at topography such as seamounts, when repeated over and over as sketched in Figure 1 , can result in a net turbulent diffusion as follows: Let the mixed layer height be $h$ and the mean time of transit from one mixed layer to another independent mixed layer be $\tau$. A particle receives an average displacement, $\alpha h\left(\alpha \sim \frac{1}{2}\right)$, within each mixed layer, then streams over some time $\tau \sim L / U$, where $L$ is the mean transit distance and $U$ the average transit velocity, then suffers another statistical displace- 
ment of order $\alpha h$. This is a random walk with a diffusion coefficient

$$
k_{v} \sim \frac{(\alpha h)^{2}}{\tau} .
$$

The diffusion coefficient will be a function of depth or isopycnal since transit times and average mixed layer heights are both functions of depth.

As shown in Figure 1, cross-isopycnal mixing is dominated by turbulent processes only at topographic boundaries. Within the interior thin, $\delta \sim 10-20 \mathrm{~m}$, anomalies have been found at distances greater than $2000 \mathrm{~km}$ from their origin, (Armi, 1978). At an assumed average velocity of $\sim 1 \mathrm{~cm} / \mathrm{sec}$ these anomalies have an age, $\tau \sim 5$ years. Their existence implies a small interior vertical eddy diffusivity $k_{v} \sim \delta^{2} / \tau \sim$ $10^{-2} \mathrm{~cm}^{2} / \mathrm{sec}$. This value is in agreement with mid-ocean diffusivity estimates from microstructure levels by Osborn and Cox (1972), Gregg, Cox and Hacker (1973) and Gargett (1976).

In order to obtain a prescription for the variation with isopycnal level of the average or "apparent" cross-isopycnal diffusivity, the vertical diffusive flux is first formally decomposed into an interior and boundary contribution. The interior contribution will be seen to be negligible in comparison to the boundary contribution. The average vertical flux is

$$
A(z) \overline{k_{v}(z) \frac{\partial c}{\partial z}}(z)=A_{\text {int }}(z) \overline{k_{v_{\text {int }}}(z) \frac{\partial c}{\partial z_{\text {int }}}}(z)+A_{\text {bound }}(z, h) \overline{k_{v_{\text {bound }}}(z) \frac{\partial c}{\partial z}}(z) .
$$

$A(z)$ is the total area of the isopycnal at level $z$; this area is made of two parts $A_{\text {int }}(z)$, the area away from boundaries, and $A_{\text {bound }}(z, h)$, the area of boundary contact at seamounts, continental rises, ridges, abyssal plains, and other bottom topography of all the mixed layers which span this isopycnal level. At any boundary these mixed layers have a height of $\sim 50 \mathrm{~m}$, (Armi and Millard, 1976) although in high current regions, for example beneath deep western boundary currents, these layers can be as tall as $\sim 250 \mathrm{~m}$ (Amos, Gordon and Schneider, 1971).

Vertical property gradients reaching the boundary are similar to property gradients in the interior water column of the basin. As discussed more fully in Armi (1979), multiple layers found above the bottommost mixed layer are rarely completely mixed indicating that separation from the boundary occurs before this assumption fails significantly. The "apparent" averaged diffusivity is then

$$
\bar{k}_{v}(z)=\frac{A_{\text {int }}(z)}{A(z)} \bar{k}_{v_{\text {int }}}(z)+\frac{A_{\text {bound }}(z, h)}{A(z)} \bar{k}_{v_{\text {bound }}}(z) .
$$

The vertical diffusivity within the boundary mixed layers is high. Armi (1978) estimated $\bar{k}_{v_{\text {bound }}} \sim 10^{2} \mathrm{~cm}^{2} / \mathrm{sec}$, similar to values estimated for bottom mixed layers from ${ }^{222} \mathrm{Rn}$ by Sarmiento et al. (1976). Typically the ratio of areas is $A_{\text {int }}(z) / A_{\text {bound }}$ $(z, h) \sim 10^{2}$. With $\bar{k}_{v_{\text {int }}}(z) \sim 10^{-2} \mathrm{~cm}^{2} / \mathrm{sec}, \bar{k}_{v_{\text {bound }}}(z) \sim 10^{2} \mathrm{~cm} / \mathrm{sec}$, 


$$
\frac{A_{\text {int }}(z) \bar{k}_{v_{\text {int }}}(z)}{A_{\text {bound }}(z, h) \bar{k}_{v_{\text {bound }}}(z)} \sim 10^{-2}
$$

which implies the dominant balance of equation (4) is given by

$$
\bar{k}_{v}(z)=\frac{A_{\text {bound }}(z, h)}{A(z)} \bar{k}_{v_{\text {bound }}}(z) \text {. }
$$

Equation (6) gives a prescription for the depth dependence of the "apparent" or average vertical eddy diffusivity. It is dependent on a ratio of surface areas, that of the boundary area spanned by the mixed layers at any isopycnal to the total surface area of the isopycnal.

The isopycnally averaged cross-isopycnal steady advective diffusive equation can now be written with a variable diffusivity coefficient as

$$
w(z) \frac{\partial c}{\partial z}-\frac{\partial}{\partial z}\left(\bar{k}_{v}(z) \frac{\partial c}{\partial z}\right)=0
$$

where $w(z)$ is the vertical velocity. Usually it is assumed that both $k_{v}(z)$ and $w(z)$ are constants, resulting in the equation

$$
P e_{v} \frac{\partial c}{\partial z}-\frac{\partial^{2} c}{\partial z}=0 \text {. }
$$

where all the dimensional terms are contained in the cross-isopycnal Peclet number

$$
P e_{v}=\frac{w z}{\bar{k}_{v}} \text {. }
$$

With an observationally inferred scale height, $z \sim 1 \mathrm{~km}$, and independent estimates either from decaying tracers, which give a second scale height assumed to balance $\left(\vec{k}_{v} / \lambda\right)^{\frac{1}{2}}$ where $\lambda$ is the decay constant, or from estimated water formation rates for $w$, an estimate for the vertical eddy diffusivity is inferred. Examples of purely vertical advective diffusive balances with constant eddy diffusivity are those of Wyrtki (1962), Munk (1966), and Craig (1969). Warren (1977a, b) has cast some doubt on the inferences from such models when either a nonconstant vertical velocity distribution or horizontal diffusion is included.

But is the observed scale height possibly due largely to the neglected variation of the apparent vertical eddy diffusivity? Here the prescription for $\vec{k}_{v}(z)$ given by equation (6) will be used to test for such a possibility. Knowledge of the vertical distribution of sources and sinks for much of the oceans is however incomplete and advection along isopycnals from multiple sources (cf. Montgomery, 1938; Iselin, 1939; Parr, 1936, 1938; Welander, 1959, 1971) makes it difficult to isolate diffusive from advective effects. This is particularly true at the thermocline for which the large horizontal variations of surface sources and sinks will act like a distribution of various isopycnal sources and sinks when isopycnal diffusion dominates cross isopycnal diffusion. Because of these difficulties, the variable cross isopycnal eddy diffusivity 
prescription will be tested in an obviously diffusive regime between two sources and sinks which are widely separated in the vertical.

The top of the deep isopycnal source will be taken at the intrusive surface of the Denmark Straits Norwegian Sea Overflow Water $\left(\sim 5000 \mathrm{~m}, \theta \cong 1.8^{\circ} \mathrm{C}\right.$, cf. Reid and Lynn, 1971, and Armi, 1978). The bottom of the sink will be the deep thermocline. Between the upper isopycnal surface, corresponding to Labrador Sea Water and the deep Mediterranean Outflow $\left(\sim 2000 \mathrm{~m}, \theta \cong 3.4^{\circ} \mathrm{C}\right.$, cf. Worthington, 1976), and the lower isopycnal surface, the Denmark Straits Overflow, there are of course other isolated sources of water, e.g., Iceland Scotland Overflow Water. However, these other sources are considerably weaker than the combined deeper sources, due to Antarctic Bottom Water and Denmark Straits Overflow which Worthington (1976) estimates at $\sim 7 \times 10^{6} \mathrm{~m}^{3} / \mathrm{sec}$ and $\sim 4 \times 10^{6} \mathrm{~m}^{3} / \mathrm{sec}$ respectively. A more detailed description would include these other sources as well as the water entrained into the North Atlantic Deep Water from the Denmark Straits Overflow as it flows around the Labrador Basin to the level of the intrusion on the Northeastern Sohm Abyssal Plain.

For the deep thermocline and below, the prescription given by equation (6) will be simplified by assuming $\bar{k}_{v_{\text {bound }}}(z)$ is only weakly dependent on depth, i.e.

$$
\bar{k}_{v}(z)=\frac{A_{\text {bound }}(z, h)}{A(z)} \bar{k}_{v_{\text {bound }}} .
$$

Beneath the thermocline, the velocity distribution is only weakly dependent on depth (cf. Sanford, 1975; Schmitz, 1978) hence the boundary diffusivity estimated in Armi (1978) as

$$
k_{v_{\text {bound }}} \sim \frac{1}{15} u_{*} h
$$

where $u *$ is the friction velocity

$$
u * \sim \frac{1}{30} U
$$

will also be only weakly dependent on depth since both $U$ and $h$ are only weak functions of depth in the deep ocean. A more sophisticated model would need to take these effects into account.

For the sake of the argument assume $P e_{v}<<1$, then

$$
\frac{\partial}{\partial z}\left(k_{v}(z) \frac{\partial c}{\partial z}\right)=0 .
$$

Substitution of potential density and the gravitational acceleration $g$ in equation 13

$$
\frac{\partial}{\partial z}\left(\bar{k}_{v}(z) \frac{g}{\rho} \frac{\partial \rho}{d z}\right)=0
$$


with the eddy diffusivity given by equation 10 yields

$$
\frac{\partial}{\partial z}\left(\frac{A_{\text {bound }}(z, h)}{A(z)} \frac{g}{\rho} \frac{\partial \rho}{d z}\right) \sim 0 .
$$

With the definitions for the Brunt-Väisälä frequency and area ratio,

$$
\begin{gathered}
N^{2} \equiv \frac{g}{\rho} \frac{\partial \rho}{d z} \\
A_{r}(z) \equiv \frac{A_{\text {bound }}(z, h)}{A(z)}
\end{gathered}
$$

equation 15 implies that

$$
A_{r}(z) N^{2}(z) \sim \text { constant }
$$

independent of depth (isopycnal) between the two deep isopycnal sources and sinks discussed.

Koczy $(1956,1958)$ and Sarmiento et al. (1976) have also used constant flux models with variable vertical eddy diffusivity to model radon distributions. These authors have found empirically that $k(z) N^{2}(z) \sim$ constant, which is similar to that given by equation (18). Their assumptions of a source in the sediment only at the local bottom with no isopycnal exchange are however incorrect in light of the evidence for boundary mixing, isopycnal mixing, and little cross isopycnal mixing in the basin interior. Their result is probably due to a source distribution of radon which is also depth dependent in the same way as the area ratio $A_{r}(z)$.

The boundary contact area ratios to be used here are computed from the boundary contact areas of each depth zone (Menard and Smith, 1966) reproduced in Table 1a. Since the area ratio defined by equation (17) is the ratio of the boundary contact area in the $\sim 50 \mathrm{~m}$ depth interval at $z$ to the total area at $z$, the hypsometric data of Menard and Smith have been recomputed in Table $1 \mathrm{~b}$ as the ratio of the boundary contact area within each depth interval to the sum of the boundary contact areas for that depth interval and all deeper ones. This quantity is the most useful one for our purposes.

For comparison with hydrographic data, averaged data from the center of the Northwestern Atlantic Basin and north-south stability sections for the Atlantic, Pacific and Indian Oceans are used.

The averaged data are from nine CTD stations taken at the Internal Wave Experiment (IWEX) site $\left(27^{\circ} 44^{\prime} \mathrm{N}, 69^{\circ} 51^{\prime} \mathrm{W}\right)$ on the Hatteras Abyssal Plain. The average of these nine profiles taken on the Knorr 34 deployment cruise for the experiment, along with the mean of two CTD profiles taken on the Knorr 36 recovery cruise, are reproduced from Tarbell et al. (1976) in Figure 2. The tabulated data computed from the data of Menard and Smith (1966) for the Atlantic Ocean (Table 1b) are plotted in Figure 3 along with the averaged data for $1 / N^{2}$ of Tarbell et al. (1976). Figure 3 shows

$$
A_{r}(z) \sim \text { constant } \bullet 1 / N^{2}(z)
$$


Table 1a. Boundary contact area for each depth zone in the oceans from Menard and Smith (1966). The figure gives the percent of total contact area for each ocean.

\begin{tabular}{lccccccr} 
& \multicolumn{7}{c}{ Depth interval in kilometers } \\
\multicolumn{1}{c}{ Ocean } & $0.2-1$ & $1-2$ & $2-3$ & $3-4$ & $4-5$ & $5-6$ & $>6$ \\
Pacific Ocean & 2.6 & 3.3 & 6.9 & 21.8 & 35.0 & 26.9 & 2.0 \\
Atlantic Ocean & 5.2 & 4.3 & 8.6 & 19.3 & 32.5 & 22.3 & 0.8 \\
Indian Ocean & 2.7 & 3.6 & 10.0 & 25.3 & 36.6 & 17.0 & 1.2
\end{tabular}

Table 1b. Ratio of boundary contact area within each depth interval to sum of boundary contact areas for that interval and deeper ones, expressed in percent for each ocean.

\begin{tabular}{lccccccc}
\multicolumn{1}{c}{ Ocean } & $0.2-1$ & $1-2$ & $2-3$ & $3-4$ & $4-5$ & $5-6$ & $>6$ \\
Pacific Ocean & 2.6 & 3.4 & 7.4 & 25 & 55 & 93 & 100 \\
Atlantic Ocean & 5.6 & 4.9 & 10 & 26 & 58 & 97 & 100 \\
Indian Ocean & 2.8 & 3.8 & 11 & 32 & 67 & 93 & 100
\end{tabular}

Between 2000 and $5000 \mathrm{~m}$ the agreement is good with the constant of proportionality being $4[(\%)$ (c.p.h.)].

For a global comparison, the north-south stability sections for the Atlantic, Pacific and Indian Oceans of Reid and Lynn (1971) are used in Figure 4. For each of the depth intervals computed from the data of Menard and Smith (1966) in Table $1 b$, a computed stability from the boundary mixing model i.e.,

$$
E(z) \sim \text { constant } \bullet 1 / A_{r}(z)
$$

is also included in the figure. The constant of proportionality is the same as found from Figure 3 (equation 20) i.e., $120\left[(\%)\left(10^{-8} \mathrm{~g} / \mathrm{cm}^{3} / \mathrm{m}\right)\right]=4[(\%)$ (c.p.h.)]. Away from the deep water sources in polar regions agreement between computed and actual distributions of density is seen in Figure 4.

The data above lend support to the hypothesis that the vertical distribution of density in the deep ocean may be due largely to vertical variation of an apparent cross isopycnal eddy diffusivity. For argument, it was assumed that the vertical Peclet number is small. It was found that the vertical distribution may be explained with a plausible boundary mixing model for the variation of vertical eddy diffusivity. The agreement between model and data is simply a statement of the hypsometric fact that the vertical length scale for the variation of the vertical eddy diffusivity, due in the model to surface area variation with depth, is similar to the length scale found for the vertical variation of the density distribution.

\section{Isopycnal property distributions}

Observational evidence now exists showing large variations in the eddy energy field of the oceans. If such variations are associated with similar large variations in 


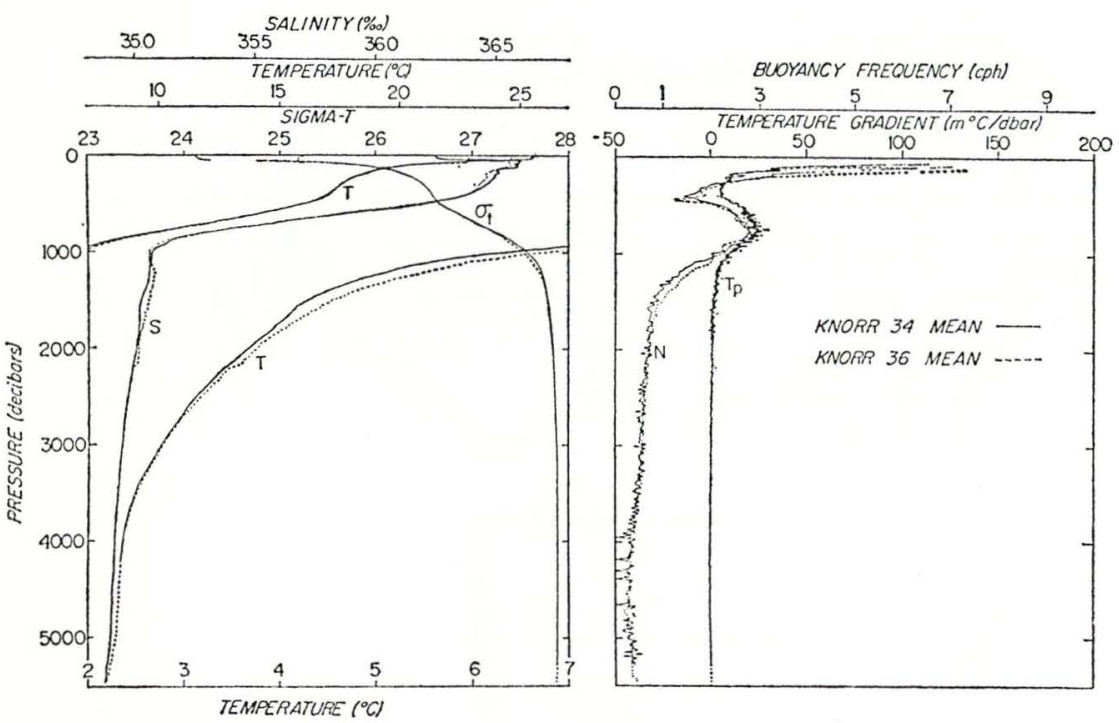

Figure 2. Mean hydrographic profiles taken during the Internal Wave Experiment (IWEX), from Tarbell et al. (1976).
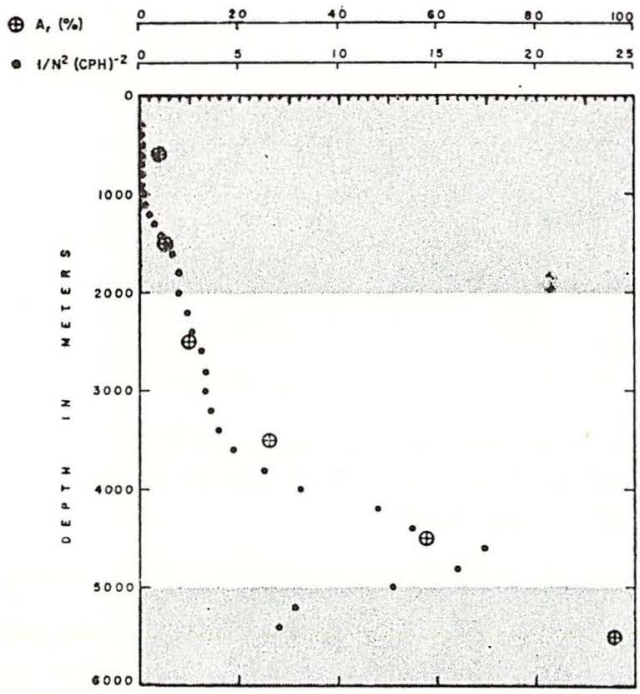

Figure 3. Comparison of computed area ratio $\left(A_{r}, \%, \oplus\right)$ as a function of depth, from the data of Menard and Smith (1966), with averaged data for inverse of the stability $\left(1 / N^{2}\right.$, c.p.h. ${ }^{-I} \bullet$ ), from Tarbell et al. (1976). As explained in the text, agreement is expected only between $\sim 2000$ and $5000 \mathrm{~m}$, i.e., between two greatly separated, in the vertical, sources and sinks. 

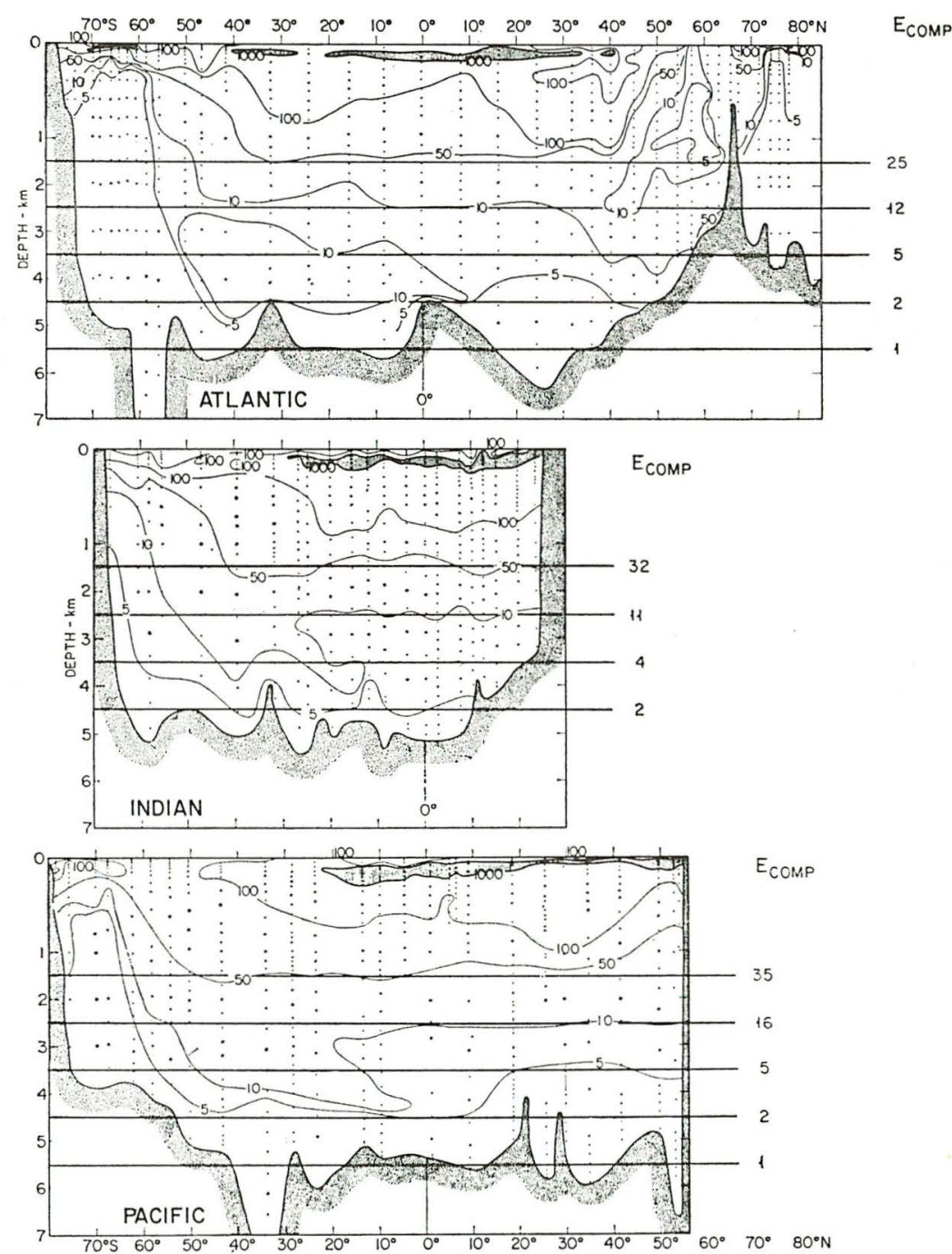

Figure 4. Comparison of north-south stability $\left(E=\Delta^{\prime} \rho / \Delta z, 10^{-8} \mathrm{~g} / \mathrm{cm}^{3} / \mathrm{m}\right)$ Sections for the Atlantic, Pacific and Indian Oceans from Reid and Lynn (1971) with computed stabilities $\left(E_{\text {comp }}\right)$ from the boundary mixing model.

the eddy diffusivity field, then such variations may be partially responsible for observed property fields. As yet only a very qualitative prescription can be given for the isopycnal diffusivity field; nonetheless, striking similarities exist between property distribution maps and eddy energy maps. These similarities will be illustrated here.

Examples of eddy field descriptions are contained in the following: the range of observed temperatures at 200 meters (Fuglister, 1954); the eddy field descriptions from fluctuations in dynamic topography and ship drifts (Wyrtki, 1975, 1976); the 
estimated eddy potential energy distribution inferred from mean square displacements of the $15^{\circ} \mathrm{C}$ and $13^{\circ} \mathrm{C}$ isotherms (Dantzler, 1977); and the eddy kinetic energy distributions from current meter arrays (Schmitz, 1977, 1978).

It will be assumed that the above descriptions are qualitatively similar to an as yet unknown eddy diffusivity field. One can expect from dimensional grounds (cf. Tennekes and Lumley, 1972, p. 135) that the isopycnal eddy diffusivity, $k_{H}$, will scale with the horizontal turbulent scales for velocity, $u^{\prime}$, and length, $l^{\prime}$, i.e.

$$
k_{H}=\alpha u^{\prime} l^{\prime} .
$$

The constant of proportionality is typically, $\alpha \sim 1 / 4$, for turbulent flows such as the two dimensional mixing layer (cf. Tennekes and Lumley, 1972, Table 4.1). For purely nondiffusive fluctuations such as Rossby waves the diffusivity is zero and $\alpha \sim$ 0 . If the length scale of the turbulent eddies is a weak function of location, for example fixed by the radius of deformation, and the proportion of nondiffusive fluctuations (waves) to diffusive fluctuations (turbulence) is some function of the eddy energy, then

$$
k_{H} \sim f\left(u^{\prime}\right)
$$

and maps of the eddy energy can be expected at least qualitatively to represent the eddy diffusivity field.

An extra complication which won't be addressed here is that the eddy diffusivity field is probably also anisotropic in the horizontal isopycnal directions. This is suggested by the dynamical constraint due to variation of planetary vorticity in the North-South direction, and no such variation in the East-West direction. Freeland et al. (1975) also present observational evidence, from the dispersion of SOFAR floats, for an anisotropic horizontal diffusivity.

The isopycnal steady advective diffusive equation can now be written with a variable isopycnal diffusivity as

$$
u \cdot \nabla c-\nabla \cdot\left(k_{H} \nabla c\right)=0 .
$$

When the diffusive term is expanded, a new advective diffusive equation can be written

$$
\left(u-\nabla k_{H}\right) \cdot \nabla c-k_{H} \nabla^{2} c=0 .
$$

The term $-\nabla k_{H}$ acts much like an additional advective field in the direction from high to low eddy diffusivity. This additional "gradient eddy diffusivity velocity" need not satisfy a continuity equation and hence may act like a divergent velocity field.

To facilitate comparison of property distributions with eddy diffusivity distributions, composite Figures 5 and 6 were prepared for the North Atlantic. These figures show strong qualitative similarities between contour intervals representing doubling of the eddy potential energy from Dantzler (1977) and contour intervals for salinity from Needler and Heath (1975) and Worthington (1976). A field description similar 


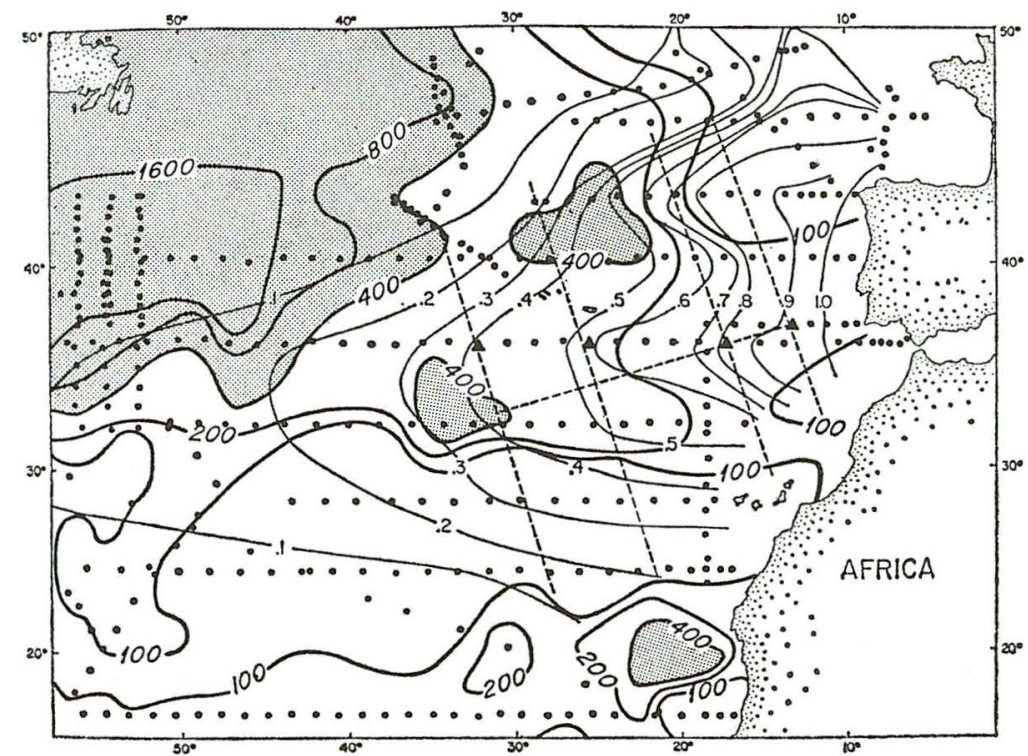

Figure 5. Comparison of salinity anomaly relative to $35.01 \%$ on the potential density 27.7 surface, from Needler and Heath (1975), with estimated potential energy per unit mass (1/2 $N^{2} \zeta^{2}$ ) arising from mean-squared displacements $\zeta$ in the thermocline, from Dantzler (1977). The closed circles give the positions of the stations used by Needler and Heath. The dark contours are those from Dantzler.

to that of Dantzler can also be seen in the range of observed temperatures at 200 meters of Fuglister (1954). Although the use of isopycnal surfaces for property distributions is preferred since advection and diffusion will occur primarily along such surfaces, the comparison with the distribution of salinity along the $10^{\circ} \mathrm{C}$ surface from Worthington (1976) is used in Figure 6 because of its large area of coverage. This presentation is similar to an isopycnal one; it underestimates slightly the salinity gradient found along an equivalent constant density surface.

The North Atlantic was chosen for comparison because both hydrographic station data and the eddy field description (over $2^{\circ}$ squares) are densest in this region. For the Pacific, qualitative similarities can also be found between the eddy energy maps of Wyrtki (1976) (over $5^{\circ}$ squares) and isopycnal property distribution maps of Reid (1965, cf. Fig. 24).

Inspection of the comparison figures, particularly Figure 6, reveals frontal-like features in the salinity distribution which coincide with areas where variations in eddy potential energy occur. Such areas are particularly prominent between $10^{\circ}$ and $20^{\circ}$ North and near the Mediterranean Outflow around 40N, 30W. As suggested by equation 24 , the fronts have the proper sense, as if an advective field were present forcing fluid from regions of high eddy diffusivity (potential energy) to low eddy diffusivity (potential energy). 


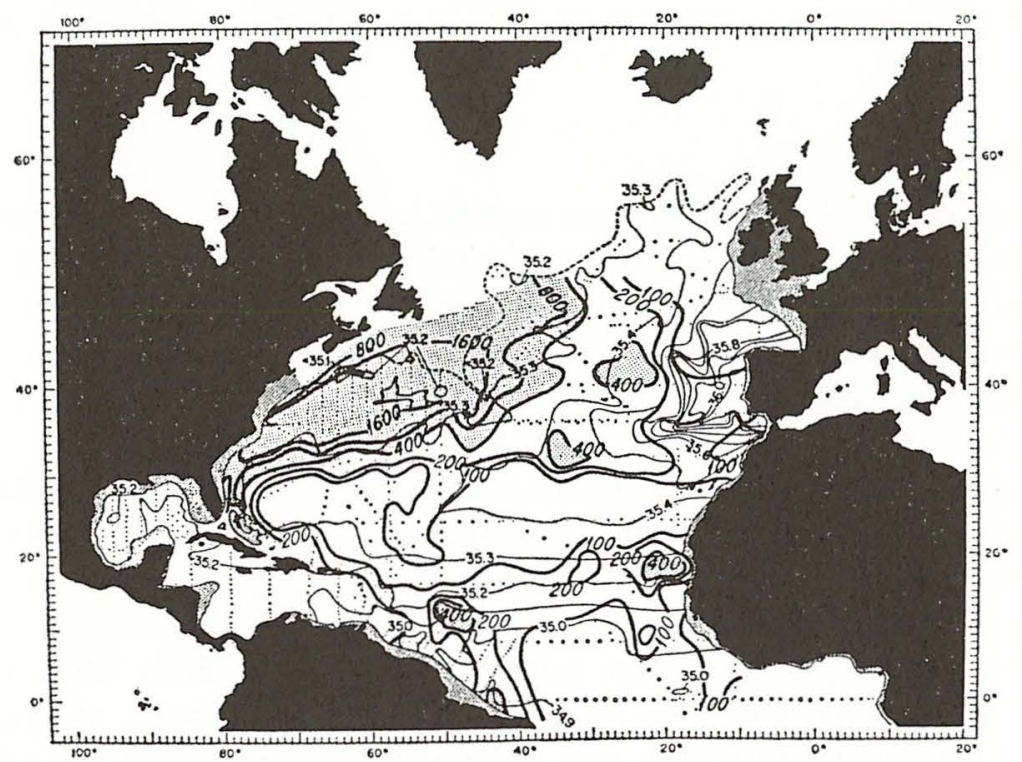

Figure 6. Comparison of salinity, $\%$ at the $10^{\circ} \mathrm{C}$ surface in the North Atlantic, from Worthington (1976) with estimated potential energy per unit mass, from Dantzler (1977). The dots indicate positions of the stations used by Worthington. The dark contours are those from Dantzler.

The use of a variable diffusivity description, as opposed to an advective diffusive one, to account for property distributions will be appropriate when

$$
\frac{\nabla k_{H}}{u} \gtrsim 1
$$

or

$$
\frac{\nabla k_{H}}{k_{H}} \gtrsim \frac{u}{k_{H}}
$$

(Refer to equation 24) For the Mediterranean Outflow, Needler and Heath (1975) found $k_{H} / u \sim 10^{8} \mathrm{~cm}(1000 \mathrm{~km})$ with a constant velocity and horizontal eddy diffusivity model. Similarly, Richardson and Mooney (1975) found good agreement between observed and calculated property distributions with a constant diffusivity gyre model for Peclet numbers $\left(P=u H / k_{H}\right)$ between 3 and 31 . Substitution of the basin scale $H \sim 5000 \mathrm{~km}$ gives a range for $k_{H} / u$ between 200 and $2000 \mathrm{~km}$ from their model. The figures of Dantzler (1977) (reproduced here in Figures 5 and 6) and Schmitz (1977, Fig. 8) show rapid variations in eddy energy on scales as small as $200 \mathrm{~km}$. Using the value of $k_{H} / u$ from Needler and Heath, these rapid variations in diffusivity imply $\nabla k_{H} / u \sim 5$. The use of a variable eddy diffusivity is then appropriate to large regions of the ocean for which the inequality of equation 25 is satisfied. There are of course important areas where obvious advective effects domi- 
nate and the inequality of equation 25 will not be satisfied, e.g. Western Boundary currents.

\section{Conclusion}

Property distributions in the oceans must be interpreted cautiously. Here, plausible spatially variable eddy diffusivity descriptions have been used to support the hypothesis that variations in eddy diffusivity may be responsible for some of the observed property distributions. Qualitative agreement was found in regions of the ocean where the "gradient eddy diffusivity velocity", a velocity-like effect for scalar fields, is large or of the same order as the advective field itself.

Two comparisons were made: the cross-isopycnal distribution of density with a vertical diffusivity prescribed by the combination of boundary mixing and isopycnal exchange; the isopycnal distribution of salinity with an eddy diffusivity inferred from the eddy potential energy field.

Further insights will come from using known advective fields when available. Sources and sinks for other properties, such as silicate and oxygen, will yield additional information since for each such scalar with a different origin, the same conservation equation must be satisfied but for a different set of boundary conditions. Similar additional insight will come from the exploitation of existing transient tracers.

Acknowledgments. My research is supported by the National Science Foundation under Grant OCE 76-81190 and by the Office of Naval Research under Contract N00014-C-0197, NR 083-400. I received helpful criticisms and comments for which I am most grateful from Eric D'Asaro, Glenn Flierl, Nick Fofonoff, Nick McCave, Joe Reid, Bruce Warren and the reviewers.

\section{REFERENCES}

Amos, A. A., A. L. Gordon, and E. D. Schneider. 1971. Water masses and circulation patterns in the region of the Blake-Bahama Outer Ridge, Deep-Sea Res., 18, 145-165.

Armi, L., and R. C. Millard, Jr. 1976. The bottom boundary layer of the deep ocean, J. Geophys. Res., 81, 4983-4990.

Armi, L. 1978. Some evidence for boundary mixing in the deep ocean, J. Geophys. Res., 83, 1971-1979.

- 1979. Reply to comments by C. Garrett. J. Geophys. Res., 84.

Brighton, P. W. M. 1978. Strongly stratified flow past three-dimensional obstacles, Quart. J. of the Roy. Met. Soc., 104, 289-307.

Craig, H. 1969. Abyssal carbon and radiocarbon in the Pacific, J. Geophys. Res., 74, 5491-5506.

Dantzler, H. L., Jr. 1977. Potential energy maxima in the tropical and subtropical North Atlantic, J. Phys. Oceanog., 7, 512-519.

Freeland, H., P. Rhines, and T. Rossby. 1975. Statistical observations of the trajectories of neutrally buoyant floats in the North Atlantic, J. Mar. Res., 33, 383-404.

Fuglister, F. C. 1954. Average temperature and salinity at a depth of 200 meters in the North Atlantic, Tellus, 6, 46-58.

Gargett, A. E. 1976. An investigation of the occurrence of oceanic turbulence with respect to finestructure, J. Phys. Oceanogr., 6, 139-156. 
Gregg, M. C., C. S. Cox, and P. W. Hacker. 1973. Vertical microstructure measurements in the Central North Pacific, J. Phys. Oceanog., 3, 458-469.

Hunt, J. C. R., W. H. Snyder, and R. E. Lawson, Jr. 1978. Flow structure and turbulent diffusion around a three-dimensional hill, Rep. No. EPA-600/4-78-041, U.S. Environmental Protection Agency, Research Triangle Park, NC 27711.

Iselin, C. O'D. 1939. The influence of vertical and lateral turbulence on the characteristics of the waters at mid-depths, EOS Trans. AGU, 414-417.

Koczy, F. F. 1956. Vertical eddy diffusion in deep water. Nature, 178, 585-586.

- 1958. Natural radium as a tracer in the ocean. Proc. of the 2nd U. N. Int. Conf. on Peaceful uses of Atomic Energy, Vol. 18, 351-357.

Menard, H. W., and S. M. Smith. 1966. Hyposometry of ocean basin provinces, J. Geophys. Res., 71, 18, 4305-4325.

Montgomery, R. B. 1938. Circulation in upper layers of southern North Atlantic, Pap. Phys. Oceanogr. Meteorol., 6, 55 pp.

Munk, W. H. 1966. Abyssal recipes, Deep-Sea Res., 13, 707-730.

Needler, G. T., and R. A. Heath. 1975. Diffusion coefficients calculated from the Mediterranean salinity anomaly in the North Atlantic Ocean, J. Phys. Oceanogr., 5, 173-182.

Osborn, T., and C. Cox. 1972. Oceanic fine structure, Geophys. Fluid Dyn., 3, 321-345.

Parr, A. E. 1936. On the probable relationship between vertical stability and lateral mixing processes, J. du Conseil Int. Pour l'Exp. de la Mer, 11, 308-313.

- 1938. Isopycnic analysis of current flow by means of identifying properties, J. Mar. Res., I, 133-154.

Reid, J. L., Jr. 1965. Intermediate waters of the Pacific Ocean, The Johns Hopkins Oceanographic Studies, no. 2, The Johns Hopkins Press, Baltimore, MD, 85 pp.

Reid, J. L., and R. J. Lynn. 1971. On the influence of the Norwegian-Greenland and Weddell seas upon the bottom waters of the Indian and Pacific Oceans, Deep-Sea Res., 18, 1063-1088.

Richardson, P. L., and K. Mooney. 1975. The Mediterranean Outflow-a simple advectiondiffusion model, J. Phys. Oceanogr., 5, 476-482.

Rossby, C.-G. 1936. Dynamics of steady ocean currents in the light of experimental fluid mechanics, Pap. Phys. Oceanogr. Meteorol., 5, 43 pp.

Sanford, T. B. 1975. Observations of the vertical structure of internal waves. J. Geophys. Res., 80, 3861-3871.

Sarmiento, J. L., H. W. Feely, W. S. Moore, A. E. Bainbridge, and W. S. Broecker. 1976. The relationship between vertical eddy diffusion and buoyancy gradient in the deep sea, Earth Planet. Sci. Lett., 32, 357-370.

Schmitz, W. J., Jr. 1977. On the deep general circulation in the Western North Atlantic, J. Mar. Res., 35, 21-28.

1978. Observations of the vertical distribution of low frequency kinetic energy in the Western North Atlantic. J. Mar. Res., 36, 295-310.

Tarbell, S., M. G. Briscoe, and D. Chausse. 1976. A compilation of moored current data and associated oceanographic observations Volume IX (1973 Internal Wave Experiment) Technical Report W.H.O.I. 75-68, Woods Hole Oceanographic Institution, Woods Hole, MA.

Tennekes, H., and J. L. Lumley. 1972. A First Course in Turbulence, M.I.T. Press, Cambridge, MA, 300 pp.

Veronis, G. 1967. Analogous behavior of homogeneous, rotating fluids and stratified, non-rotating fluids, Tellus, 19, 326-335.

Warren, B. A. 1977a. Shapes of deep density-depth curves, J. Phys. Oceanogr., 7, 338-344. 
1977(b). Note on interpreting e-folding depths, in A Voyage of Discovery, M. Angel ed., Pergamon Press, New York, $69 \mathrm{pp}$.

Welander, P. 1959. An advective model of the ocean thermocline, Tellus, 11, 309-318.

1971. The thermocline problem. Phil. Trans. Roy. Soc. of London, A 270, 415-421.

Worthington, L. V. 1976. On the North Atlantic circulation, The Johns Hopkins Oceanographic Studies, no. 6, The Johns Hopkins Press, Baltimore, MD, 110 pp.

Wyrtki, K. 1962. The oxygen minima in relation to ocean circulation, Deep-Sea Res., 9, 11-23.

1975. Fluctuation of the dynamic topography in the Pacific Ocean. J. Phys. Oceanogr., 5, 450-459.

Wyrtki, K., L. Magaard, and J. Hager. 1976. Eddy energy in the oceans, J. Geophys. Res., 81, 2641-2646.

Received: 10 August, 1978; revised: 11 May, 1979.

Printed in U.S.A. for the Sears Foundation for Marine Research, Yale University, New Haven, Connecticut, 06520, U.S.A.

Van Dyck Printing Company, North Haven, Connecticut, 06473, U.S.A. 


\section{MANDATORY DISTRIBUTION LIST \\ FOR UNCLASSIFIED TECHNICAL REPORTS, REPRINTS, AND FINAL REPORTS \\ PUBLISHED BY OCEANOGRAPHIC CONTRACTORS \\ OF THE OCEAN SCIENCE AND TECHNOLOGY DIVISION \\ OF THE OFFICE OF NAVAL RESEARCH}

(REVISED NOVEMBER 1978)

1 Deputy Under Secretary of Defense

(Research and Advanced Technology)

Military Assistant for Environmental Science

Room 30129

Washington, D.C. 20301

Office of Naval Research

800 North Quincy Street

Arlington, VA 22217

3 ATTN: Code 483

1 ATTN: Code 460

2 ATTN: 102B

1 CDR J. C. Harlett, (USN)

ONR Representative

Woods Hole Oceanographic Inst.

Woods Hole, MA 02543

Commanding Officer

Naval Research Laboratory

Washington, D.C. 20375

6 ATTN: Library, Code 2627
12 Defense Documentation Center Cameron Station

Alexandria, VA 22314

ATTN: DCA

Commander

Naval Oceanographic Office NSTL Station

Bay St. Louis, MS 39522

1 ATTN: Code 8100

ATTN: Code 6000

ATTN: Code 3300

1 NODC/NOAA

Code D781

Wisconsin Avenue, N.W.

Washington, D.C. 20235 
UNCLASSIFIED $12 / 79$

SECURITY CLASSIFICATION OF THIS PAGE (When Date Entored)

\begin{tabular}{|c|c|c|}
\hline \multicolumn{2}{|r|}{ REPORT DOCUMENTATION PAGE } & \multirow{2}{*}{$\begin{array}{l}\text { READ INSTRUCTIONS } \\
\text { BEFORE COMPLETING FORM } \\
\text { 3. RECIPIENT'S CATALOG NUMBER }\end{array}$} \\
\hline & 2. GOVT ACCESSION NO. & \\
\hline \multirow{2}{*}{\multicolumn{2}{|c|}{$\begin{array}{l}\text { 4. TITLE (and Subttlo) } \\
\text { EFFECTS OF VARIATIONS IN EDDY DIFFUSIVITY } \\
\text { ON PROPERTY DISTRIBUTIONS IN THE OCEANS }\end{array}$}} & $\begin{array}{l}\text { 5. TYPE OF REPORT O PERIOD COVERED } \\
\text { Technical }\end{array}$ \\
\hline & & $\begin{array}{l}\text { 6. PERFORMING ORG. REPORT NUMBER } \\
\text { WHOI CON. NO. } 4209\end{array}$ \\
\hline \multicolumn{2}{|r|}{$\begin{array}{l}\text { 7. AUTHOR(o) } \\
\text { Laurence Armi }\end{array}$} & $\begin{array}{l}\text { 8. CONTRACT OR GRANT NUMBER(ब) } \\
\text { N00014-76-C-0197; } \\
\text { OCE 76-81190 }\end{array}$ \\
\hline \multicolumn{2}{|r|}{$\begin{array}{l}\text { 9. PERFORMING ORGANIZATION NAME AND ADDRESS } \\
\text { Woods Hole Oceanographic Institution } \\
\text { Woods Hole, MA } 02543\end{array}$} & $\begin{array}{l}\text { 10. PROGRAM ELEMENT, PROJECT, TASK } \\
\text { AREA Q WORK UNIT NUMBERS } \\
\text { NR } 083-400\end{array}$ \\
\hline \multirow{2}{*}{\multicolumn{2}{|c|}{$\begin{array}{l}\text { 11. CONTROLLING OFFICE NAME AND ADDRESS } \\
\text { NORDA } \\
\text { National Space Technology Laboratory } \\
\text { Bay St. Louis, MS } 39529 \\
\text { 14. MONITORING AGENCY NAME \& ADDRESS(If dilforent from Controlling Office) }\end{array}$}} & $\begin{array}{l}\text { 12. REPORT DATE } \\
\text { December } 1979 \\
\text { 13. NUMBER OF PAGES }\end{array}$ \\
\hline & & $\begin{array}{l}\text { 15. SECURITY CLASS. (of this roport) } \\
\text { UnClaSS ifjed } \\
\text { 15e. DECLLASSIFICATION/DOWNGRADING } \\
\text { SCHEDULE }\end{array}$ \\
\hline
\end{tabular}

17. DISTRIBUTION STATEMENT (of the abotract entoped in Block 20, if different from Ropopt)

18. SUPPLEMENTARY NOTES

Reprinted from "Journal of Marine Research, Volume 37, 3, 1979, pp. 515-529".

19. KEY WORDS (Continue on poverse sido /f neceseary and Identlfy by block number)

1. Eddy diffusivity

2. Property distributions

3. Oceanic scalars

20. ABSTRACT (Continue on reverse side if neceseary and ldentlfy by block number)

The hypothesis that variations in eddy diffusivity may be responsible for some of the observed distributions of oceanic scalars is explored. A gradient in eddy diffusivity affects property distributions much as would an additional velocity field from regions of high to low eddy diffusivity. In support of such an interpretation, the cross-isopycnal distribution of density is compared with an eddy diffusivity prescribed by the combination of boundary mixing and isopycnal exchange. Since the surface area available for (Cont. on 
boundary mixing varies with depth, similar variations are reflected in

property distributions. For isopycnal distributions, an eddy diffusivity

field inferred from the eddy potential energy field description of Dantzler

(1977) is compared with the salinity distribution from the Mediterranean Outflow. 


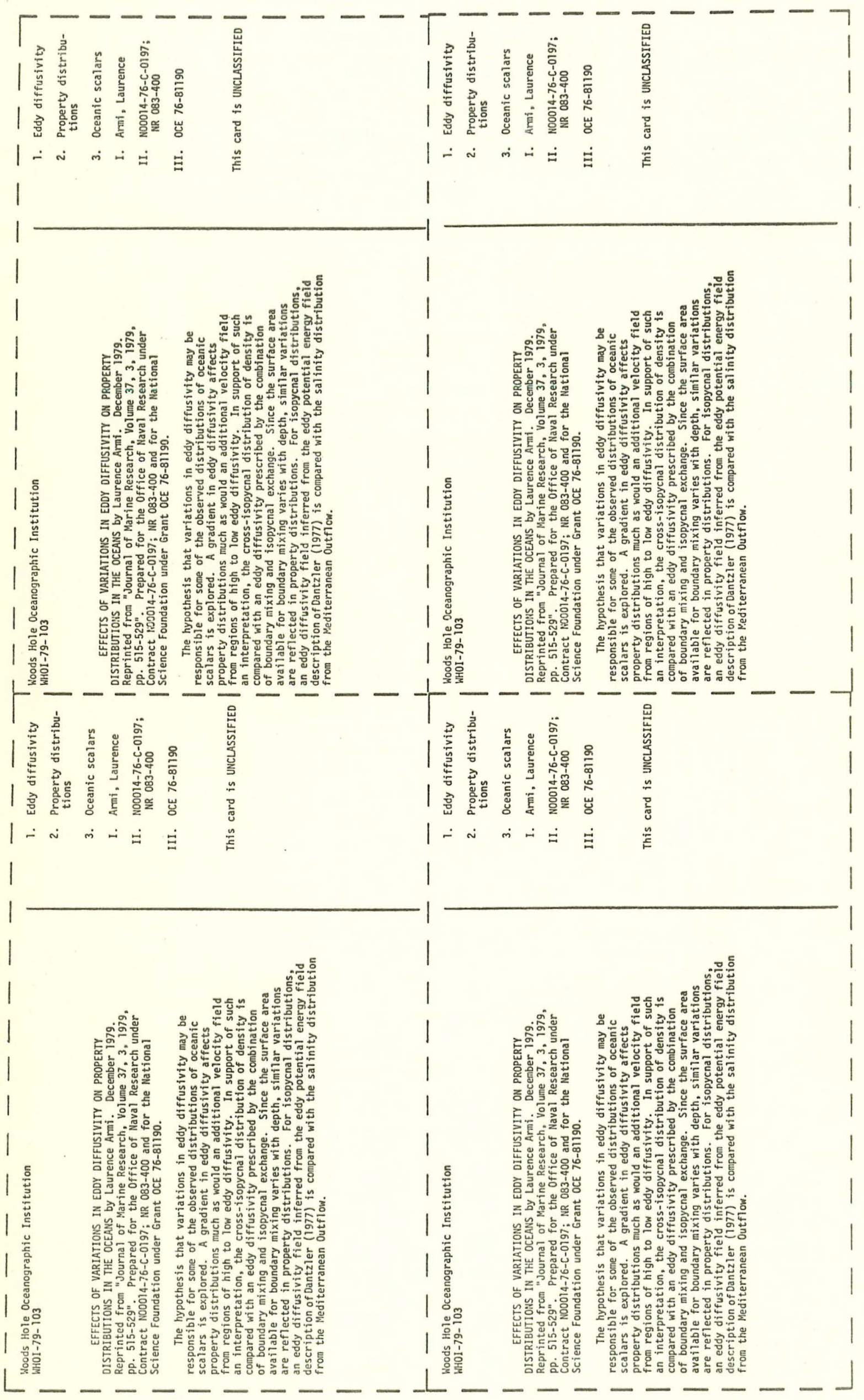

